\title{
A construção social e histórica da profissão docente uma síntese necessária*
}

\author{
LIBÂNIA NACIF XAVIER \\ Universidade Federal do Rio de \\ Janeiro, Rio de Janeiro, RJ, Brasil
}

RESUMO

O estudo apresenta uma síntese da produção teórica que aborda o processo de construção social e histórica da profissão docente em circulação nos últimos trinta anos. Prioriza as publicações de pesquisas realizadas fora do Brasil, principalmente as de língua inglesa e francesa, mas que circularam entre nós com tradução para o português do Brasil ou de Portugal. Inclui também publicações em língua espanhola, bem como aquelas resultantes de intercâmbios acadêmicos entre pesquisadores brasileiros e portugueses. Ao final, indica algumas potencialidades teóricas e práticas do conjunto de estudos selecionados.

\section{PALAVRAS-CHAVE}

profissão docente; história da educação; pesquisa educacional.

* O estudo se insere nas atividades do Programa de Intercâmbio CAPES-FCT (2008-2009) e contou com o apoio do Conselho Nacional de Desenvolvimento Científico e Tecnológico (CNPq), por meio do Edital Universal (2008-2009). 


\section{THE SOCIAL AND HISTORICAL CONSTRUCTION OF THE TEACHING PROFESSION: A NECESSARY OVERVIEW}

\section{ABSTRACT}

The study provides an overview of the theory that addresses the process of social and historical construction of the teaching profession in the last thirty years. Publications from research outside Brazil are prioritized, especially in English and French, but have been translated into Brazilian Portuguese or Portuguese from Portugal. It also includes publications in spanish, as well as those resulting from academic exchanges between Brazilian and Portuguese researchers. At the end, the study suggests some potential theoretical and practical selected studies.

KEYWORDS

teaching profession; history of education; educational research.

\section{LA CONSTRUCCIÓN SOCIAL E HISTÓRICA DE LA PROFESIÓN DOCENTE: UNA SÍNTESIS NECESARIA}

\section{RESUMEN}

El presente estudio presenta una síntesis de la producción teórica que aborda el proceso de construcción social e histórica de la profesión docente, en circulación en los últimos treinta años. Prioriza las publicaciones de investigaciones realizadas fuera de Brasil, principalmente las de lengua inglesa y francesa, pero que circularon entre nosotros con traducciones al portugués de Brasil o de Portugal. Incluye, también, publicaciones en lengua española, así como aquellas resultantes de intercambios académicos entre investigadores brasileños y portugueses. Finalmente, indica algunas potencialidades teóricas y prácticas del conjunto de estudios seleccionados.

profesión docente; historia de la educación; investigación educacional. 
A produção de relatórios de pesquisa, de artigos e de livros sobre a questão docente é abundante tanto no Brasil como no contexto internacional. A existência de tantos trabalhos que se voltam para a compreensão da profissão docente expressa, por um lado, a complexidade do tema e, por outro, o interesse da comunidade universitária em compreender a questão. Expressa também a insistência dos governos em interferir no trabalho docente, moldando-o de acordo com o projeto de sociedade que o sustenta. Contudo, podemos entender tal abundância como reveladora da inexistência de consenso em relação à questão, ou ainda como indicadora do quanto os professores vêm sendo silenciados pela fala dos governos e dos especialistas. Seja qual for a explicação ideal desse fenômeno, para aqueles que pretendem melhor compreender e assim contribuir para articular o potencial explicativo da variedade de estudos a que temos acesso, torna-se imperativo elaborar uma síntese, ainda que provisória, da produção sobre o tema.

Nessa perspectiva, o presente estudo visa socializar a referida síntese, elaborada no curso de pesquisas que temos desenvolvido sobre o processo de construção histórica da profissão docente. Para tanto, destaca as contribuições da produção acadêmica sobre a história e a sociologia da profissão docente nos últimos trinta anos. Priorizarmos as publicações de pesquisas realizadas fora do Brasil, mas que têm circulado entre nós, com tradução para o português do Brasil ou de Portugal. Além disso, incluímos publicações em língua espanhola, bem como aquelas resultantes de intercâmbios acadêmicos entre pesquisadores brasileiros e portugueses.

Por certo, a análise dos modos de apropriação de obras estrangeiras pela produção brasileira constitui questão de grande relevância, mas é bom lembrar que esta requer outros esforços de pesquisa e, por isso, não fará parte do escopo deste artigo. Cabe assinalar que o conjunto de pesquisas sobre a temática da profissão docente extrapola em muito o recorte efetuado neste artigo, em vista da extensão, diversidade e alta qualificação das pesquisas desenvolvidas entre nós. Portanto, o artigo não se propõe a fazer um estado da arte da produção sobre essa temática. ${ }^{1}$

É necessário, por isso, esclarecer os critérios e as limitações da própria síntese que aqui se apresenta, tendo em vista que, como não poderia deixar de ser, ela é resultado de escolhas e renúncias, bem como da necessidade de efetuar recortes, fazer convergirem dados e responder aos questionamentos que têm conduzido nossas incursões no enfrentamento da complexidade do tema e das inúmeras possibilidades de abordagem disponíveis. Desse modo, a produção brasileira aparece apenas no último tópico, focalizando pesquisas realizadas na perspectiva da história da educação e da profissão docente e que resultaram de intercâmbio entre pesquisadores brasileiros e portugueses.

Ao longo do texto, nós inserimos algumas notas de rodapé, de modo a pontuar iniciativas e obras que representam estudos consolidados no âmbito da produção nacional e constituem referências regulares e relevantes para as pesquisas na área.

1 Outros estudos já se debruçaram sobre a produção brasileira, como o estado da arte da produção acadêmica sobre formação de professores no período 1990-1998, organizado por Marli André (2002). 
O texto se encontra estruturado em seis tópicos. O primeiro procura delimitar as particularidades da profissão docente. Para tanto, recorre a uma bibliografia introduzida no Brasil nos anos 1990, por meio de coletâneas publicadas em Portugal e posteriormente divulgadas entre nós, bem como da publicação de artigos em revistas nacionais.

O segundo tópico versa sobre a produção sociológica de língua francesa, aqui representada pelas contribuições de François Dubet (2002) e Claude Dubar (2005). O terceiro tópico aborda o resultado de pesquisas publicadas originalmente em língua inglesa, divulgadas por meio de revistas impressas e eletrônicas. Uma das que consideramos representativa é de autoria do pesquisador britânico Martin Lawn (2000) e a outra, da pesquisadora norte-americana Mary Dalton (1996). Assim como os estudos dos sociólogos franceses, as duas pesquisas em língua inglesa também abordam o tema das identidades docentes, porém de pontos de vista bastante peculiares. A essas duas abordagens, nós acrescentamos a referência a Ivor Goodson (2010), tendo em vista que alguns de seus estudos conferem centralidade às histórias de vida dos professores e, desse modo, enriquecem a análise dos seus processos e de suas dinâmicas identitárias.

O quarto tópico contempla pesquisas que incidem sobre as condições de desenvolvimento do trabalho docente, retomando o referencial marxista para analisar o processo de proletarização do magistério.

A partir do quinto tópico, as abordagens historiográficas ganham centralidade, destacando-se a contribuição incontornável do pesquisador português António Nóvoa (1987, 2002 e 2005), em seu estudo sobre o processo de profissionalização docente. Trata-se de uma pesquisa que aborda o tema na perspectiva da longa duração, de modo a compor uma reconstrução social e histórica da gênese e do desenvolvimento da profissão docente na Europa ocidental. Para além da perspectiva global e generalizante que o referido autor nos oferece, esse mesmo tópico remeterá o leitor às abordagens etnográficas e ao questionamento a respeito da pertinência de se utilizar o conceito de cultura docente no estudo desse grupo profissional. Para situar esta questão, analisamos a contribuição de dois pesquisadores portugueses, a saber: Jorge Ávila de Lima (2000) e Thelmo Caria (2000).

O sexto e último tópico comenta a produção historiográfica resultante do intercâmbio entre pesquisadores portugueses e brasileiros. Nas considerações finais são indicadas algumas das potencialidades teóricas e práticas do conjunto de estudos selecionados.

\section{PARTICULARIDADES DA PROFISSÃO DOCENTE}

As concepções que comumente se difundem sobre a função da escola e o papel do professor, em geral, aparecem associadas a duas noções recorrentes: a noção de que a educação escolar encontra-se em crise e a conviç̧ão de que é preciso promover uma mudança. Contra essa corrente, alguns estudos apresentam argumentos que nos permitem desestabilizar certas ideias e noções naturalizadas pela familiaridade que temos com o modo de vida escolar (Hutmacher, 1992). 
Do ponto de vista dos formuladores e dos gestores das políticas educacionais, o desejo de fazer da prática pedagógica e da ação do professor um trabalho embasado em parâmetros racionais, aliado à expectativa de obter desse trabalho resultados previsíveis e imediatos, tem gerado confusões, críticas infundadas e representações equivocadas sobre os diversos aspectos da prática educativa. Em contrapartida, certo descrédito em relação às instituições, em especial à escola, tem contribuído para reforçar uma imagem bastante instável do papel da escola e da influência positiva exercida pelo(a) professor(a) na vida de seus alunos e no próprio desenvolvimento social de forma mais geral. Tudo isso, a nosso ver, é consequência de uma percepção pouco fundamentada a respeito das potencialidades e dos limites da escola e do papel do professor na vida individual de seus alunos e na própria dinâmica social.

A esse respeito, é importante registrar os avanços alcançados, destacando-se as contribuições de estudos que propiciaram a renovação das pesquisas sobre a profissão docente, a partir da reflexão sobre as especificidades dos saberes que constituem matéria-prima do ofício do professor (Tardif; Lessard; Lahaye, 1991); sobre as formas de organização do trabalho pedagógico (Hutmacher, 1992); e as tensões que marcam as práticas docentes (Perrenoud, 1993).

Os primeiros desenvolveram uma pesquisa sobre a construção do saber docente em situações de trabalho, a partir da qual pudemos destacar três questões que estão no centro dessa problemática. São elas: 1) as características particulares do saber docente; 2) os aspectos que distinguem o saber docente do saber universitário - no âmbito das chamadas "ciências da educação" - e dos conhecimentos incorporados nos cursos de formação de professores; 3 ) as relações entre as três instâncias de produção de saberes - a formação universitária, a formação pedagógica e a profissionalização ocorrida na prática cotidiana e no ambiente escolar.

As pesquisas desenvolvidas por esses autores demonstraram, entre outros aspectos, que os saberes docentes são temporais, plurais, e heterogêneos, personalizados e situados e, ainda, carregam consigo as marcas do seu objeto, que é o ser humano. Com isso, os autores contrapõem o caráter subjetivo do trabalho docente aos ideais de racionalidade e objetividade que marcaram, durante muito tempo, as orientações de alguns especialistas em planos e políticas dirigidos aos professores.

Philippe Perrenoud (1993) abordou a tensão entre a busca de uma metodologia racional do trabalho docente e a improvisação e dispersão que acompanham as múltiplas decisões que o professor é levado a tomar no seu trabalho diário. Seus estudos têm contribuído para desestabilizar certas noções que, muitas vezes, são tomadas como parâmetros numa avaliação do trabalho docente. Com frequência, as avaliações negativas acerca do trabalho do professor se fundamentam em bases insuficientes, na medida em que as práticas pedagógicas não se realizam apenas como mera concretização de modelos didáticos ou de esquemas racionais e conscientes de ação, mas, pelo contrário, são dirigidas pelo habitus do professor em consonância com certos esquemas de pensamento e de ação que alicerçam as inúmeras microdecisões tomadas na sala de aula (idem, p. 35).

Considerando o caráter pessoal do ato de ensinar, vem se desenvolvendo entre os estudiosos do assunto a perspectiva de cruzar as histórias de vida dos professores com o desenvolvimento profissional da categoria docente. A atenção 
para as histórias de vida dos professores tem se colocado como um importante dado para ampliarmos o conhecimento a respeito da educação escolar em suas mais diversas dimensões. Para Huberman (2007), o interesse renovado pelas histórias de vida pode ajudar a estimular novas investigações que contribuam para produzir um pensamento propriamente pedagógico - e não apenas antropológico, histórico, psicológico ou sociológico - sobre a profissão docente. Afirma-se, por meio desse tipo de abordagem, o caráter subjetivo da própria profissão, chamando atenção para a dinâmica dos processos de negociações identitárias (Dubar, 2005) acionados ao longo das trajetórias docentes, tanto no âmbito individual como nos contextos institucionais, como veremos a seguir.

\section{SOCIALIZAÇÃO E IDENTIDADE PROFISSIONAL: A CONTRIBUIÇÃO DA SOCIOLOGIA FRANCESA}

A abordagem sociológica francesa sobre socialização e identidade profissional tem orientado boa parte dos estudos sobre profissão docente no Brasil. Nesses estudos, prevalece a preocupação em explicar a ideia recorrente de crise das instituições escolares e compreender suas repercussões sobre o trabalho docente. Tais questões acabam por incentivar o estudo das negociações identitárias, chamando atenção para os processos de construção - individual e coletiva - das identidades docentes. Os pesquisadores estão buscando perceber em que medida a observação das negociações em torno da construção de identidades profissionais pode revelar aspectos ainda pouco explorados a respeito dos constrangimentos políticos, das interações sociais e das dimensões simbólicas que permeiam as dinâmicas identitárias desse grupo profissional.

Destacamos as contribuições de Claude Dubar, com o livro $A$ socialização: construção das identidades sociais e profissionais - em 1997 publicado em Portugal pela Porto Editora; no Brasil foi publicado pela Martins Fontes, em reimpressão de 2005 - e o livro de François Dubet, Le declin de l'institution, publicado na França em 2002, ainda sem tradução para o português, mas circulando em língua espanhola em reedição de 2006, com o título El declive de la institución - profesiones, sujetos e individuos ante la reforma del Estado.

No livro A socialização, Claude Dubar $(1997,2005)$ analisa os mecanismos de construção das identidades profissionais que se desenvolvem ao longo da trajetória profissional dos indivíduos e se articulam ao próprio processo de socialização. $\mathrm{O}$ tema é abordado a partir de dois eixos fundamentais, a saber: 1) eixo sincrônico, ligado a um contexto de ação e a uma definição de situação, em um espaço culturalmente marcado, e 2) eixo diacrônico, ligado a uma trajetória subjetiva e a uma interpretação da história pessoal, socialmente construída. Como demonstra o autor, é na articulação desses dois eixos que cada um se define simultaneamente, como ator de um sistema determinado e produto de uma trajetória específica.

A elucidação das formas de identificação socialmente pertinentes em uma dada esfera de atuações - objetivas, subjetivas e reconhecidas socialmente, as quais o autor denomina formas identitárias - articula dois sentidos dos termos socialização 
e identidade: a socialização relacional dos atores em interação em um contexto de ação (as identidades para o outro) e a socialização biográfica dos atores engajados em uma trajetória social (as identidades para si). Resultam, por fim, em uma concepção de ator que se define a um só tempo pela estrutura de sua ação e pela história de sua formação.

Desse modo, a teoria sociológica apresentada por Dubar tem como ponto central a articulação entre dois processos identitários heterogêneos. O primeiro, que diz respeito à atribuição de identidade pelas instituições e pelos pares em interação com o profissional, deve ser analisado dentro dos sistemas de ação nos quais o indivíduo está inserido. Esse processo resulta de relações de força entre os atores envolvidos e da legitimidade dos atributos que são impostos coletivamente e que levam a formas variáveis de etiquetagem. ${ }^{2} \mathrm{O}$ outro processo refere-se à incorporação da identidade pelos próprios indivíduos e só pode ser analisado considerando-se as trajetórias sociais por meio das quais os indivíduos constroem identidades para si. Nesse caso, a legitimidade irá depender daquilo que subjetivamente tem importância para o indivíduo.

A construção das identidades se faz, portanto, na articulação entre os sistemas de ação que propõem identidades virtuais e as trajetórias vividas pelos sujeitos, por meio e no seio das quais se formam as identidades reais, em um processo constante de negociação, que se realiza dentro de um determinado campo de possibilidades. Para esse autor, tanto as esferas do trabalho e do emprego quanto as da formação constituem domínios pertinentes das identificações sociais dos indivíduos, sempre pensadas como configurações relativamente estáveis, mas igualmente evolutivas. Essa análise nos parece particularmente sugestiva numa dupla direção: a relação entre biografia e identidade profissional e a relação intergeracional.

Dubar considera que todas as identidades são construções históricas - sociais e de linguagem - e, como tal, são acompanhadas por racionalizações e reinterpretações que às vezes se fazem passar por essências intemporais. Mesmo considerando que a formação da identidade constitui essencialmente um problema de geração, ele alerta que cada geração a constrói com base nas categorias e nas posições herdadas da geração precedente, mas também através das estratégias identitárias desenvolvidas nas instituições pelas quais os indivíduos passam e que eles contribuem para transformar. Essa construção identitária adquire uma importância particular nos campos do trabalho, do emprego e da formação, nos quais os indivíduos buscam conquistar o reconhecimento de sua competência profissional, ao mesmo tempo em que participam na atribuição dos status sociais a seus pares.

A abordagem de Dubet (2002) sobre as profissões vinculadas à educação, à saúde e ao serviço social o leva a caracterizar a profissão docente, assim como a dos profissionais da saúde e da assistência social, como profissões que se remetem ao trabalho sobre o outro. O autor parte do pressuposto de que esse tipo de trabalho, nas suas origens, foi concebido como um programa institucional, que designa particularmente

2 Esse termo designa o ato de promover uma classificação socialmente partilhada a respeito das identidades dos indivíduos. 
um modo de socialização ou um tipo de relação com o outro. O referido livro assinala que, há quase meio século, a escola se viu submetida a duas críticas, ambas radicais. A primeira reduz a instituição e o trabalho escolar a uma vontade de poder e de dominação. Mais liberal e mais política, a segunda crítica opõe a índole fechada das instituições à diversidade e ao fluxo constante das demandas sociais, de informações e de políticas públicas. Frente a esses fluxos, as instituições se mostram como burocracias rígidas, testemunhos de um passado dominado pelo Estado centralizador.

Como observou o autor, a consciência de viver em um mundo aberto, pluralista e desagregado provém de que a maior parte das instituições escolares perdeu seu monopólio sobre a difusão de conhecimentos socialmente relevantes. Isso porque - no momento atual, em que o modo escolar de socialização já extrapolou os muros da escola - as crianças encontram acesso a muitos outros meios que thes abrem distintos universos culturais, e a cultura escolar se torna uma cultura entre outras, mais exigente e oficial, porém não mais a única. Ele explica que essa perda do monopólio cria um sentimento de diminuição da legitimidade e da influência da escola e dos professores, justamente quando os aparatos escolares têm tanto poder e tanta influência sobre o destino de cada um, como jamais tiveram antes.

Para esse autor, a sociologia crítica também afetou as instituições escolares, na medida em que os profissionais adquiriram uma dificuldade a mais para lidar com a indisciplina. Esta se transformou num problema, porque aqueles responsáveis por impor a disciplina, os professores, devem também percebê-la como manifestação justa. Assim, ao mesmo tempo em que sofreram uma perda de legitimidade de sua autoridade, os professores se viram obrigados a lidar com o aumento da resistência dos usuários dessas instituições em submeter-se às normas da disciplina escolar, muito frequentemente distantes das referências culturais de seu meio de origem. O controle da disciplina tem requerido dos professores um trabalho de justificação permanente, para o que eles necessitam mobilizar constantemente seus atrativos pessoais. Tal situação já seria suficiente para falar não apenas na crise de identidade perante demandas variadas, e não raro divergentes, a que estão sujeitos os professores na sociedade contemporânea, como também indica a emergência de aspectos típicos do que se convencionou chamar de mal-estar profissional.

Em que pese o caráter sociológico de seus estudos, tanto Dubet (2006) quanto Dubar (1997) atribuem forte ênfase à abordagem histórica dos processos de construção social das profissões. Enquanto o primeiro enquadra a consolidação e a crise das instituições escolares e a valorização social do professor nos limites do projeto de constituição da modernidade ocidental, o segundo chama atenção para a cadeia geracional que constrói e remodela, incessantemente, as identidades profissionais, os desenhos institucionais e as dinâmicas sociais que se definem e que reconfiguram os modos de atuação pessoal e profissional.

Nesse aspecto, tanto o pesquisador britânico Martin Lawn (2000) quanto a norte-americana Mary Dalton (1996) desenvolvem uma abordagem que se apoia na análise dos mecanismos de gestão ou, de modo mais enfático, nos modos de fabricação das identidades docentes. Por seu turno, Ivor Goodson (2010) chama atenção para a importância do foco sobre os indivíduos e suas subjetividades, apoiado no estudo das histórias de vida de professores. 


\section{ABORDAGENS EM LÍNGUA INGLESA SOBRE A FABRICAÇÃO DAS IDENTIDADES DOCENTES}

Uma abordagem que incide sobre a questão da produção e gestão da identidade docente provém dos estudos de Martin Lawn (2000), para quem o Estado promove a produção de identidades dos docentes através de suas leis e regulamentos, de seus discursos e intervenções na mídia, dos programas de formação, certificação e qualificação de professores, das políticas de publicação dirigidas aos professores, entre outras formas de intervenção. $\mathrm{O}$ autor destaca que a produção de uma dada identidade é móvel e flexível o suficiente para se adaptar aos projetos políticos em curso, de modo a recompor o controle do Estado sobre a ação e o trabalho docente, adotando estratégias variadas de acordo com o contexto em que se inscreve.

Considera, portanto, que os professores são parte importante de um projeto educativo e podem aparecer como sombras, representantes ou sujeitos. Aparecem em destaque quando algo foge ao contrato de neutralidade política e comportamental estabelecido entre os docentes e a sociedade representada pelo Estado, desencadeando um estado de pânico moral acionado pela desconfiança do poder que os professores detêm sobre a parte fraca da sociedade, ou seja, sobre suas crianças. Por meio desse tipo de abordagem, torna-se possível desenvolver estudos que objetivem explicitar os imperativos práticos e ideológicos da gestão do Estado sobre a identidade dos professores, identificados por meio da observação de determinadas regras de conduta profissional, das condições de ingresso, desempenho e valorização da carreira, bem como pela atribuição de certas qualidades, funções e papéis sociais que os documentos governamentais, tais como os materiais de orientação curricular e as propostas pedagógicas oficiais declaram esperar desses profissionais.

Outros estudos apontam que o Estado não detém o controle exclusivo da gestão das identidades dos professores, conforme demonstrou a pesquisadora norte-americana Mary Dalton (1996). A autora analisou 26 filmes veiculados nos Estados Unidos, ${ }^{3}$ nos quais a imagem do bom professor e da boa professora é construída com base no tipo heroico, dotado de uma personalidade especial, que luta contra a instituição escolar e os colegas acomodados para desempenhar seu papel dentro do mais alto nível de comprometimento estético-ético-político. Retratados como tipos renegados, indivíduos fora do convencional, o(a) bom(a) professor(a) dos filmes de Hollywood se envolve pessoalmente com seus alunos, quase sempre rompendo com as regras institucionais para ajudá-los a completarem a transição entre a escola e o mundo exterior. No entanto, conclui a autora, os professores aparecem como tipos heroificados e individualizados. Jamais atuam em grupo, não concebem a escola e o ensino como um trabalho coletivo. Por isso, esses filmes rendem belos espetáculos, porém os professores neles retratados jamais conseguirão promover mudanças duráveis na instituição escolar, porque

3 Entre os filmes, são citados: Ao mestre com carinho (1967); Conrack (1974); Escola da desordem (1984); Um tira no jardim de infância (1990); Mr. Holland: adorável professor (1996), entre outros. 
não acreditam na escola como instituição pública e tampouco conseguem articular um projeto coletivo de mudança da escola e do ensino.

Mais preocupado em entender os currículos escolares em suas relações com as histórias de vida dos professores, Ivor Goodson (2010) destaca a importância das vozes dos professores no processo de investigação sobre a escola. $\mathrm{O}$ autor considera que a análise das questões curriculares e das práticas pedagógicas pode se beneficiar da atenção para com as histórias de vida dos professores, pois suas formas de atuação no contexto escolar estão diretamente ligadas às suas experiências. $\mathrm{O}$ autor argumenta que os dados sobre as vidas dos professores constituem fatores importantes para a investigação educacional, já que os estilos de vida dos professores, dentro e fora da escola, bem como suas identidades e culturas ocultas têm impacto sobre os modelos de ensino, assim como sobre as práticas educativas.

De igual modo, ele considera que os estágios e decisões referentes à carreira só podem ser analisados no seu próprio contexto (idem, p. 72), o que nos leva a concluir que os entrelaçamentos entre estilos pessoais e subjetivos com os contextos institucionais e as prescrições profissionais interferem nas concepções e práticas docentes, e será a análise desses dados que permitirá ao pesquisador compreender elementos únicos do processo de ensino. Para o autor, os estudos referentes às vidas dos professores situam o indivíduo em relação com a história do seu tempo, permitindo-nos encarar a intersecção da história de vida com a história da sociedade, esclarecendo, assim, as escolhas, contingências e opções que constituem os contextos de ensino, em suas práticas e representações. ${ }^{4}$

Se tomarmos as contribuições desses autores para refletirmos sobre a condição docente nos dias atuais, seremos levados ao sentimento de mal-estar profissional. O processo de expansão das oportunidades escolares tem levado ao aumento das responsabilidades sociais dos professores, ampliando, também, as exigências sobre os resultados do seu trabalho, impondo, cada vez mais intensamente, que eles promovam alterações no modo como vinham desenvolvendo seu ofício. Isso requer um processo de renegociação identitária, colocando o professor diante de seus limites profissionais. Esse processo exacerba, também, o sentimento de desamparo perante as autoridades governamentais que, muitas vezes, não têm respostas para o encaminhamento de problemas cotidianos, tal como o da violência urbana (entre outros), que tem interferido, cada vez mais, na dinâmica das escolas.

4 É justo assinalar a consolidação de pesquisas que abordam a formação e a autoformação docente com base nas narrativas pessoais e em outras fontes autobiográficas, valorizando a subjetividade como modo de produção de saberes e de construção de sentidos na vida e nos percursos profissionais dos professores. A realização regular dos Congressos Internacionais de Pesquisa (Auto)Biográfica (CIPA), a partir de 2004, e a publicação da Coleção Pesquisa (Auto)Biográfica $\infty$ Educação, em parceria com a coleção francesa (Auto)Biographie $\infty$ Education, ambas dirigidas por Christine Delory-Momberger, Maria da Conceição Pesseggi e Elizeu Clementino de Souza, demonstram a dimensão que esses estudos alcançaram no âmbito da pesquisa sobre a temática da profissão docente. 


\section{ABORDAGENS SOBRE AS CONDIÇÕES DE TRABALHO E A SAÚDE DOS PROFESSORES}

A esse respeito, os estudos do pesquisador espanhol José Manoel Esteve (1999) têm concedido uma atenção especial para as relações entre as novas demandas educacionais e a saúde dos professores. $\mathrm{O}$ autor associa essa sensação de mal-estar a um conjunto de mudanças sociais que ocorreram nos últimos anos, tais como o advento da escola de massas, o desenvolvimento de fontes de informação alternativas à escola, a mudança nas expectativas em relação ao sistema de ensino e o aumento das exigências em relação ao trabalho do professor, provocando a ruptura do consenso em torno dos objetivos do ensino, do papel da escola e das funções do professor. Tal situação foi agravada, por um lado, pela difusão das críticas sociológicas ao funcionamento da escola no sistema capitalista, como nos referimos anteriormente, assim como pela desvalorização salarial do professor a qual agravou a desvalorização social. Os reflexos mais visíveis do mal-estar que atinge os professores podem ser observados na grande incidência de pedidos de licença para tratamento de saúde, em particular aquelas atribuídas a transtornos psíquicos que estão sendo tratados como síndrome do esgotamento profissional, também conhecida como síndrome de burnout.

Tais efeitos foram agravados nos últimos anos pela adoção de políticas de caráter democratizante. Se, por um lado, essas políticas expressam importantes avanços dos movimentos sociais e da própria democracia, a sua implantação tem sido feita, muitas vezes, de modo demagógico, desconsiderando a necessidade de se criarem condições adequadas para sua efetivação e continuidade.

As consequências da progressiva universalização do ensino sobre o trabalho dos professores da educação básica originaram questões centrais nos estudos sobre a profissão docente, em especial nos estudos de caráter sociológico. ${ }^{5}$ Nóvoa (2002) assinala que, nos últimos cinquenta anos, o processo de universalização do ensino levou a que a escola e os professores assumissem uma importância cada vez maior e, ao mesmo tempo, mais complexa. Por isso mesmo, os professores também se encontram cada vez mais expostos à avaliação pública e, acrescentamos nós, vêm sendo submetidos a diferentes esquemas de medição dos resultados de seu trabalho, submetidos a um sem número de avaliações, índices e rankings para medir o nível de aprendizagem dos alunos e definir a posição da escola, do sistema ou do país nas escalas hierárquicas produzidas pelos organismos de regulação da educação.

Além disso, os processos de estabilização e aprofundamento democrático têm reforçado as expectativas de inclusão social por meio da escolarização. Nesse processo, a adoção de políticas de diversidade, com vistas a garantir os direitos de

5 A criação da Rede Latino-Americana de Estudos sobre Trabalho Docente (REDESTRADO), em 1999, constitui um passo importante para a consolidação desse campo de estudos. A rede tem promovido, regularmente, intercâmbios entre pesquisadores dedicados ao tema da profissão docente de diferentes áreas disciplinares, associações sindicais e universidades sediadas na América Latina. Disponível em: <http:// www.redeestrado.org/web/1/1.php?idioma=>. Acesso em: 23 fev. 2014. 
grupos específicos, está atuando sobre as orientações políticas para a educação, introduzindo novas demandas ao trabalho do professor, como a ampliação de conhecimentos e disposições para atuar junto a alunos com necessidades especiais, tais como deficiências físicas e psíquicas; grupos beneficiados por cotas raciais; grupos que abrangem políticas de diversidades sexuais; entre outras demandas. Esse processo tem contribuído para uma exacerbação das tarefas docentes e, diante da falta de infraestrutura para apoiar os professores no atendimento a essas novas demandas, temos assistido a um processo de precarização do trabalho escolar (Oliveira, 2004), com consequências negativas na saúde dos professores (Esteve, 1999). Nesse sentido, os estudos sobre as condições de trabalho dos professores começam a ganhar um espaço de reflexão cada vez mais amplo. ${ }^{6}$

A questão sinalizada nos leva a outro tipo de abordagem, que tem exercido forte influência nas análises históricas e sociológicas sobre a profissão docente. Essa abordagem provém das chamadas teorias da proletarização. Os artigos publicados no Brasil, ainda na década de 1990, em um dossiê temático da revista Teoria e Educação (1991), apresentam as linhas gerais desse debate teórico, identificando seus principais autores e respectivas teses centrais e envolvendo pesquisadores de nacionalidades diversas.

Um autor principal nesse debate é o pesquisador norte-americano Michael Apple (2006). Ele aborda a perda de controle dos professores sobre a seleção, organização e produção dos saberes que constituem a matéria-prima de seu trabalho, identificando aí um dos principais fatores de sua desqualificação profissional. Por sua vez, o pesquisador espanhol Mariano Enguita (1991) observa o aspecto de ambiguidade da docência, a qual, segundo o autor, estaria a meio caminho entre a profissionalização e a proletarização. Compartilhando características de ambos os extremos, os docentes encontram-se submetidos à autoridade de seus empregadores, ao mesmo tempo em que lutam para ampliar sua margem de autonomia no processo de trabalho e suas vantagens em relação à distribuição de renda, poder e prestígio. Tal situação é demonstrada a partir da análise das características dos grupos profissionais solidamente constituídos: competência, vocação, licença, independência e autorregulação. A tese central de Enguita é a de que os docentes encontram-se submetidos a processos cuja característica (e resultado) é a mesma para a maioria dos trabalhadores assalariados: a proletarização.

De modo geral, os teóricos da proletarização identificam como principal fator desse processo a lógica racionalizadora do capital, a qual impõe a rotinizaçẫo do trabalho, o excesso de especialização e a hierarquização, contribuindo para a desqualificação (separação entre concepção e execução do trabalho) e falta de autonomia (perda de controle e de poder decisório sobre o próprio trabalho) dos professores. De certo

6 Uma iniciativa extremamente relevante para o desenvolvimento de pesquisas nesse eixo de observação é o Dicionário "trabalho, profissão e condição docente", organizado pelo Grupo de Estudos sobre Política Educacional e Trabalho Docente (GESTRADO-UFMG). Ele contém verbetes elucidativos das categorias relacionadas com o trabalho, as políticas e as práticas docentes e está disponível em: <http://www.gestrado.org/?pg=dicionarioapresentacao>. Acesso em: 24 fev. 2014. 
modo, Marta Esther Jiménez Jaén (1991) problematiza as teorias da proletarização docente, ressaltando que esse processo assume formas específicas que nem sempre permitem a assimilação dos professores à classe operária. Entretanto, enquanto os teóricos da proletarização consideram as analogias com a classe operária, nas quais as diferenças existentes entre as duas categorias tendem a desaparecer, a autora lembra que, de modo inverso, as diferenças encontradas são reveladoras das especificidades do processo sofrido por essa categoria profissional.

O próprio Enguita (1991, p. 44) relativiza a questão, considerando que os docentes se movem “dentro dos limites da ambiguidade própria das semiprofissões". A definição dependerá, sobretudo, da capacidade da categoria em alcançar unidade e solidariedade positivas no sentido de resistir às pressões postas pelos manipuladores do poder. A esse respeito, vários autores têm assinalado a importância da gestão coletiva do trabalho docente.

O desafio é, então, o de compreender uma situação extremamente ambígua, pois ao mesmo tempo em que os professores alcançaram relativa estabilidade e regularidade em seu processo de trabalho, eles também se encontram submetidos ao controle do Estado, coerente com a condição de funcionários públicos. Desse modo, a legitimidade intelectual e a visibilidade social, então adquiridas, se chocam com os mecanismos de controle e de gestão das identidades profissionais dos professores, limitando sua autonomia.

Essa ambivalência que caracteriza a profissão docente - metade intelectuais (livre-pensadores) e metade representantes do Estado (burocratas) - representa, de certa forma, um dilema na definição da identidade profissional desse grupo. Nesse aspecto, a construção de uma abordagem sócio-histórica da temática em questão representa um avanço para a compreensão das particularidades que constituem o processo de profissionalização da categoria docente.

\section{PROFISSIONALIZAÇÃO E CULTURA DOCENTE}

O pesquisador português António Nóvoa (1987) propõe um conceito de profissão que articula quatro processos imbricados na configuração da profissão docente. Assim, o processo de profissionalização envolve primeiramente a prática de determinada atividade em tempo integral ou, ao menos, enquanto ocupação principal. A questão da profissionalização só se coloca a partir do momento em que certo domínio social é ocupado por um conjunto de indivíduos que lhe consagram a maior parte do seu tempo de trabalho, buscando dessa forma sua subsistência.

Para além disso, Nóvoa ressalta a importância da criação, pelas autoridades públicas ou estatais, de um suporte legal para o exercício da atividade, sob a forma, por exemplo, de uma licença ou diploma. Esse segundo processo é particularmente importante para as profissões de tipo burocráticas porque define um quadro legal de acesso à profissão. Normalmente, esse quadro estabelece as condições necessárias, principalmente as que se relacionam com as competências exigidas para o ingresso na profissão, bem como institui procedimentos de recrutamento bem definidos. A definição do conteúdo dessas competências seria objeto de disputa entre o Estado e os diferentes grupos profissionais. Em contrapartida, o status legal delimita o campo 
de exercício profissional e se constitui em um dos mais importantes instrumentos de que os profissionais dispõem tanto para a proteção e melhoria dos seus privilégios quanto para a reivindicação do monopólio da atividade que exercem.

O terceiro processo supõe o estabelecimento de procedimentos para a aquisição de um corpo de saberes e de saber-fazer próprio da profissão, através de uma formação específica, especializada e longa. Do ponto de vista do autor, essa formação não pode ser adquirida apenas pelo aprendizado prático e deve conter referências teóricas oferecidas em um quadro acadêmico e institucionalizado. As instituições de formação não transmitem apenas conhecimentos e técnicas, mas contribuem também para a difusão de normas éticas e deontológicas, e para o desenvolvimento de um espírito de solidariedade entre os futuros membros do corpo profissional.

E o quarto processo se constitui na organização de associações profissionais com múltiplos objetivos: definir as normas de acesso à profissão; controlar seu exercício; permitir a demarcação, a preservação e o alargamento do campo social de exercício da profissão; defender os interesses socioeconômicos e profissionais dos seus membros; proteger as normas éticas e deontológicas estabelecidas. Essas associações podem ter status e papéis muito diferenciados, de acordo com as diversas profissões, e seu poder é também bastante heterogêneo. De qualquer forma, a constituição delas significa um momento importante no processo de organização de uma profissão.

Nóvoa (idem) chama atenção para o fato de que essas dimensões e etapas devem ser estudadas em estreita relação com a evolução do status social dos membros de uma profissão, já que não se pode esquecer que o processo de profissionalização é um empreendimento coletivo de mobilidade social. Nesse sentido, a história de um grupo profissional tem como eixo central a inserção e as funções sociais que este eixo contempla, bem como os projetos de sociedade de que são portadores. Desse modo, torna-se impraticável conceber a existência de um tipo ideal de profissão, pois cada grupo requer do pesquisador uma atenção particular à sua própria gênese e desenvolvimento. Aspectos como a diversidade e a fragmentação caracterizam a profissão docente e interferem na constituição de uma base profissional comum, mas nem por isso impedem a configuração de traços culturais próprios.

A questão da fragmentação da categoria docente tem sido considerada um obstáculo à profissionalização, bem como uma dificuldade a mais na coordenação de lutas coletivas e na produção de consensos mínimos por meio dos quais se possam empreender ações profissionais, políticas e de abrangência social. De fato, dada a heterogeneidade e a fragmentação que marcam esse grupo profissional, o termo cultura docente não pode ter como base uma visão monolítica a respeito das crenças, valores e ideologias ou da ação e interação dos professores. Em contrapartida, não podemos negar os processos por meio dos quais são construídos consensos e representações sociais, modos de agir e interagir entre os professores, modos estes que marcam uma identidade e uma cultura comuns, de acordo com as experiências vividas nos contextos de trabalho e/ou de participação colegiada.

Em uma instigante revisão de literatura, Jorge Ávila de Lima (2000) apresenta várias concepções a respeito da noção de cultura profissional e avalia a importância desse tipo de abordagem para a compreensão das bases que conformam as 
identidades, os modos de pensar e de agir desse grupo profissional. Para o autor, a cultura entendida como "padrões de significado e de ação" concede um lugar importante às questões de interação e interdependência no estudo das culturas profissionais dos professores. A importância de examinar essas culturas do ponto de vista da interação social decorre do fato de elas especificarem um modo dominante e legítimo de relacionamento profissional entre os docentes. "Fazer e agir é culturalmente tão importante como sentir e pensar" (idem, p. 64). Assim é interessante considerar as culturas dos professores não apenas como conjuntos de valores, representações e normas, mas também como modos de ação e padrões de interação consistentes e relativamente regulares que eles interiorizam, produzem e reproduzem durante as (e em resultado das) suas experiências de trabalho.

É nessa perspectiva que se situa a abordagem de Thelmo Caria (2000). A despeito da heterogeneidade que marca esse grupo profissional, o autor considera que os professores partilham uma cultura que "realiza um trabalho simbólico sobre si mesma, fazendo parecer igual aquilo que é social e culturalmente heterogéneo" (idem, p. 83). O autor observa o quanto essa heterogeneidade - de origem social, de formação, de posição institucional, salarial, de projeto individual, social ou profissional - pode ser geradora de conflitos e constrangimentos.

Em contrapartida, diante do fato de estarem frequentemente expostos à avaliação pública - dos alunos, das famílias, do governo, da opinião pública -, os professores também percebem que dificilmente poderão exercer total controle sobre seu trabalho, tendo em vista a permanente vigilância a que se encontram submetidos. Frente a essa situação, eles se conformam em exercer um poder periférico. Para tanto, eles restringem sua autonomia ao trabalho direto com seus alunos em sala de aula, evitando criar distinção no contexto escolar em torno das inovações e dos acertos, seja do trabalho de seus pares, seja de sua própria performance, "cultivando as semelhanças pelos silêncios de algumas práticas e pelos consensos de sentido sobre outras" (Caria, 2007, p. 132).

O que se pode observar com base na abordagem apresentada pelo autor é que a cultura profissional dos professores não estimula a participação nas estruturas de poder da escola ou do sistema, muito menos cultiva a diferenciação e hierarquização interna ao grupo, tendo em vista o entendimento consensual de que o maior ganho (ou o ganho mais seguro) que o grupo entende poder alcançar é evitar expor sua heterogeneidade e, portanto, evidenciar suas divergências, poupando-se de constrangimentos externos e de possíveis conflitos internos. Desse modo, são deixadas do lado de fora da escola as possibilidades de partilha de projetos coletivos, seja de caráter político, tal como nos sindicatos, seja de cariz profissional, como nas associações científicas e de ensino.

\section{A HISTÓRIA DA PROFISSÃO DOCENTE NO BRASIL E EM PORTUGAL}

Finalizamos o panorama apresentado até aqui, procurando identificar, ainda que de modo indicativo e pontual, os avanços atuais e as perspectivas futuras que se colocam em relação ao estudo da história da profissão docente no Brasil e em Portugal. Começaremos por apresentar um balanço retrospectivo que incide, 
sobretudo, na produção de estudos publicados até os anos 1990 e procura atualizar algumas afirmações pertinentes a esse período, para, posteriormente, vislumbrar perspectivas atuais e tendências futuras.

Com base em um levantamento preliminar, constatamos algumas características comuns no que tange à produção acadêmica sobre o tema mais geral: profissão docente. Em ambos os países, chama atenção a grande quantidade de estudos que se voltam para o tema da profissão docente, sendo mais numerosa no que se refere às suas condições atuais do que às de sua história. Nesse conjunto, havia, até 2006, uma maior incidência de estudos sobre a formação docente, em detrimento de temáticas que se voltam para a carreira profissional, condições de trabalho e associativismo docente. ${ }^{7}$

Sobre essa última temática, cabe citar o estudo pioneiro de Denice Catani (2003) que, a partir da análise da Revista de Ensino, reconstitui a história da Associação Beneficente do Professorado Público de São Paulo, articulando temas como o associativismo docente e a utilização dos impressos na organização do ensino nesse estado. ${ }^{8}$ Ainda no âmbito da história do associativismo docente, merece registro a publicação de Vicentini e Lugli (2009), com o título História da profissão docente no Brasil: representaçóes em disputa, resultado do esforço por sistematizar a história dos movimentos docentes no Brasil dos séculos XIX e XX, em especial por meio da identificação de suas associações profissionais. Nesse empenho, as autoras lograram mapear um campo de estudos ainda pouco explorado pela produção de pesquisas no âmbito da história da educação.

A formação de redes de pesquisadores interessados em temáticas comuns, bem como nas histórias conectadas, tem levado à publicação de instigantes estudos, no Brasil e em Portugal. A esse respeito, merece registro o Projeto Estudos Comparados sobre a Escola no Brasil e em Portugal no século XIX e XX (Nóvoa; Catani, 2000), que introduziu novas possibilidades de pesquisa no âmbito da história da profissão docente em perspectiva comparada, levando em consideração as vizinhanças linguísticas e culturais entre esses dois países, particularmente por meio do exame de impressos pedagógicos, tais como manuais e registros autobiográficos de professores, em circulação nos dois países (Vicentini; Rodrigues, 2004),

7 Em pesquisa anterior, foram levantados 26 artigos publicados nas três principais revistas brasileiras da área da educação (segundo avaliação da Coordenação de Aperfeiçoamento de Pessoal de Nível Superior - CAPES), cobrindo os anos de 2000 a 2006. Nessa amostra, foi possível observar uma acentuada preocupação com o problema da formação docente (70\%), em detrimento dos estudos que analisavam questões relacionadas com a carreira e as experiências de associativismo docente (30\%). Acreditamos que uma atualização desses dados provavelmente revelará o crescimento de estudos sobre carreira e condições de trabalho.

8 Os estudos sobre o associativismo docente ganharam maior visibilidade com os encontros ligados à formação de uma rede internacional de pesquisas sobre associativismo e sindicalismo docente, organizados regularmente a partir de 2009. Tais encontros contribuíram para reunir a dispersa produção de pesquisas sobre essa temática num site próprio e promoveram a publicação de uma coletânea sobre o mesmo tema (Dal Rosso, 2008). 
observando-se o modo como estes foram produzidos e apropriados no contexto de "desenvolvimento e difusão da escola de massas" (Correia; Silva, 2002, p. 5).

A utilização dos impressos como fonte para o estudo da história da educação, em geral, e para o estudo da profissão docente, em particular, tornou-se uma linha de pesquisa profícua, figurando como fonte e/ou objeto de estudo, sobretudo na perspectiva comparada. Entre os estudos que tomam os impressos pedagógicos como objetos ou como fontes de pesquisa, há os que optam por trabalhar com revistas e manuais pedagógicos (Carvalho, 2006; Fernandes, 2008); com as bibliotecas particulares (Mogarro, 2006), focalizando a circulação de ideias e saberes (Hilsdorf, 2006); ou perscrutando o cruzamento de livros, revistas e modelos pedagógicos nos dois lados do Atlântico (Bastos; Mogarro, 2009; Xavier; Mogarro, 011). Nessa perspectiva, jornais e revistas destinados ao professorado são percebidos como instâncias que desempenham papel crucial não apenas na circulação como também na produção de saberes caros à profissão. ${ }^{9}$

Outro projeto de intercâmbio entre pesquisadores brasileiros e portugueses teve como resultado a publicação do livro intitulado História da escola em Portugal e no Brasil: circulação e apropriação de modelos culturais, organizado por Joaquim Pintassilgo, Marcos Cezar de Freitas, Maria João Mogarro e Marta Maria Chagas de Carvalho (2006). Nele a seção relativa à cultura impressa e circulação de saberes pedagógicos apresenta resultados de pesquisas relativas aos modelos pedagógicos e culturais em circulação no Brasil e em Portugal, observando a circulação e a participação dos atores sociais implicados na vida escolar. Nessa linha, são analisados manuais pedagógicos de formação de professores, além de outros impressos e equipamentos como livros, bibliotecas e revistas especializadas.

Segue-se a essa obra o livro organizado por Joaquim Pintassilgo e Lurdes Serrazina (2009), analisando o aspecto institucional na formação de professores em perspectiva histórica e comparada, apresentando estudos em parceria com pesquisadores brasileiros (ver Mogarro; Martinez, 2009; Mogarro; Zaia, 2009). Tais estudos vêm contribuindo para a reavaliação histórica e historiográfica dos processos de produção e circulação de modelos pedagógicos, propiciando uma renovação na historiografia sobre a história da escola e da profissão docente, bem como têm evidenciado a pluralidade de dispositivos científicos, religiosos, políticos e pedagógicos que envolvem o funcionamento da escola e os papéis sociais desempenhados pelos professores.

Ainda na produção resultante de intercâmbios Brasil-Portugal, merece registro o desenvolvimento de estudos articulados sobre a história da profissão docente. Tais pesquisas possibilitam o conhecimento simultâneo dos processos de construção social da profissão por meio de recortes temporais e espaciais específicos. Inicialmente, buscou-se perquirir aspectos comuns e, ao mesmo tempo, particulares dos processos de profissionalização da atividade docente em um arco

9 Tais estudos foram facilitados pela organização de obras coletivas que reuniram informações sobre a imprensa de educação e ensino, coordenadas por pesquisadores europeus como Pierre Caspard (1991), na França, e António Nóvoa (2005) em Portugal. 
temporal bastante amplo (séculos XIX, XX e XXI), tendo como eixo aglutinador as ações estatais sobre o grupo, assim como as mobilizações que marcaram a busca de autonomia e de interferência na própria constituição da profissão.

Nessa perspectiva, há estudos sobre os impactos das Reformas Pombalinas no processo de profissionalização docente (Cardoso, 2002; Mendonça; Cardoso, 2007; Mendonça, 2010); sobre a emergência das escolas normais (Lopes; Martinez, 2007); sobre o associativismo docente em contextos de construção democrática (Lélis; Xavier; 2009; Xavier, 2013); e sobre valores católicos e representações de professores (Magaldi; Neves, 2007), entre outros. Sobre o conjunto de publicações citadas, há que se destacar o interesse pelo estudo da história dos professores pós-primários, tendo em vista a pouca atenção que esses vêm recebendo da historiografia da educação.

Uma contribuição significativa do conjunto de pesquisas realizadas em intercâmbio internacional refere-se ao estudo da história da profissão docente no mundo luso-brasileiro, numa perspectiva de longa duração, tentando entendê-la em um duplo contexto, caracterizado, por um lado, pelo processo de formação dos sistemas estatais de ensino e, por outro, pelo processo de institucionalização das ciências da educação, o qual se articula por uma via de mão dupla ao próprio processo de profissionalização do professor. Conforme observaram Souza e Martinez (2009, p. 210), tais estudos apresentam, hoje, um olhar problematizador, tendo como denominador comum a análise das práticas discursivas que operam no interior dos diferentes espaços sociais e nos ajudam a perceber nuances das relações entre as instituições de formação e os saberes produzidos e postos em circulação, assim como evidenciam os valores e as ações coletivas mobilizadas em momentos-chave do processo de construção histórica da profissão docente.

\section{CONSIDERAÇÕES FINAIS}

Concluindo a apresentação desse panorama de referências internacionais e de resultados de intercâmbios entre pesquisadores brasileiros e portugueses, destacamos algumas questões relevantes para a compreensão do processo de construção sócio-histórica da profissão, bem como das características culturais próprias a esse grupo profissional.

Inicialmente, cabe destacar a atenção que a questão da identidade profissional tem recebido nos estudos nacionais e internacionais. Essa atenção vem atendendo ao interesse por perceber as particularidades da profissão e, desse modo, identificar os óbices que se colocam à compreensão de seus limites e potencialidades. Entre os estudos selecionados, constam, também, aqueles que abordam as características culturais específicas dos professores. Nesse aspecto, procurou-se dar destaque aos estudos que chamam atenção não apenas para os valores, representações e normas correntes, mas também para os modos de ação e os padrões de interação regulares que os professores interiorizam, produzem e reproduzem em suas experiências de trabalho (Lima, 2000).

A produção teórica reunida nesse artigo considera, ainda, as mudanças provocadas na organização do trabalho e nas representações sobre a profissão docente, operadas nos últimos 50-60 anos, com o advento da escola de massas. 
Um aspecto que aparece como pano de fundo nessa produção tem relação com o que Dubet (2006) chamou de declínio da instituição. Trata-se, em linhas muito gerais, de encarar o crescente descrédito nos benefícios da modernidade, com suas promessas de inclusão e ascensão social pela escola, bem como o questionamento ao potencial redentor do conhecimento científico. Esses processos interferem no reconhecimento social da função docente, causando nos professores sensações de mal-estar, assim como um incômodo provocado pela suspeita relativa aos atributos positivos de seu próprio trabalho.

Acrescente-se a essas questões o fim das utopias políticas apoiadas na exemplaridade de sociedades organizadas segundo o modelo comunista e socialista. É claro que todos esses processos são dinâmicos e passíveis de reversão intelectual, política e profissional. Contudo, constituem ingredientes que, no mínimo, exercem um efeito negativo para a conformação de identidades engajadas, otimistas e confiantes no valor social do trabalho docente e, logo, para a conformação de sua atuação profissional.

Em que pesem as lacunas ainda existentes no âmbito dos estudos sobre a história da profissão docente, as tradições de pesquisa aqui identificadas representam avanços no que tange à produção de uma percepção mais acurada sobre determinadas representações e expectativas em torno do papel do professor e das potencialidades e limites da escola. Esse é, a nosso ver, o ponto a partir do qual esses estudos provocam o redimensionamento das análises vigentes, sobretudo no chamado senso comum sobre a função da escola e o papel do professor.

Nesse esforço de síntese, tornou-se possível perceber alguns princípios centrais que contribuem para melhor compreendermos a problemática da profissão docente. Entre eles, destacamos: 1) a importância de reconhecer que a escola e o professor são construções históricas e que, portanto, nem sempre foram vistos ou se fizeram perceber da forma como são vistos hoje em dia; 2) a percepção de que a escola é responsável pela permanente criação de um público, ou seja, pela socialização dos indivíduos, que, cada vez mais, dependem da experiência escolar e, portanto, da intervenção do professor para se tornarem pessoas capazes de se inserir e de conviver em sociedade; 3) a constatação de que, nos dias atuais, a escola e o professor estão assumindo uma importância cada vez maior e, ao mesmo tempo, tendem a se tornar alvo de críticas que extrapolam os limites de seu preparo profissional e de suas condições de trabalho, sendo, frequente e injustamente, responsabilizados pelos insucessos escolares.

Por fim, ressaltamos a importância de se considerar as potencialidades, os limites e as particularidades da atuação do professor e do trabalho escolar, percebido em sua configuração histórica, social e cultural. Tal esforço de conhecimento e compreensão das particularidades dessa profissão oferece instrumentos que permitem evitar tratá-los como panaceia para a solução de todas as mazelas sociais. Só assim será possível atenuar a culpa que o chamado senso comum atribui ao professor e à escola quando as crianças não aprendem, alimentando a falsa ideia de que a escola e o professor podem superar os obstáculos interpostos aos excluídos em uma sociedade desigual e injusta. 


\section{REFERÊNCIAS}

Авrahão, Maria Helena Mena Barreto (Org.). A aventura autobiográfica: teoria e empiria. Porto Alegre: EDIPUCRS, 2004.

(Org.) Autobiografia e formação humana. Porto Alegre: EDIPUCRS, 2010.

André, Marli. Formação de professores no Brasil (1990-1998). Série Estado do Conhecimento, n. 6. Brasília, DF: MEC/COMPED, 2002. Disponível em: <http://www. publicacoes.inep.gov.br/arquivos/formacao_de_professores_148.pdf>. Acesso em: 23 fev. 2014.

Apple, Michael. Ideologia e currículo. Porto Alegre: Artmed, 2006.

Bastos, Maria Helena Câmara; Mogarro,Maria João. Manuais de história da educação em Portugal e no Brasil (séculos XIX e XX). In: Araújo, Marta (Org.). Histórias comparadas da educação. Brasília: Liber Livros, 2009. p. 241-184.

CArdoso, Tereza Fachada Levy. As luzes da educação: fundamentos, raízes históricas e prática das aulas régias no Rio de Janeiro (1759-1834). Bragança Paulista: EDUSF, 2002. CARIA, Thelmo. A cultura profissional dos professores - o uso do conhecimento em contexto de trabalho na conjuntura dos anos 1990. Lisboa: Fundação Calouste Gulbenkian de Cultura, Fundação para a Ciência e a Tecnologia, 2000.

. A cultura profissional do professor de ensino básico em Portugal: uma linha de investigação em desenvolvimento. Sísifo. Revista de Ciências da Educação, Lisboa, n. 3, p. 125-138, 2007. Disponível em: <http://sisifo.fpce.ul.pt >. Acesso em: 18 fev. 2014.

Carvalho, Marta Maria Chagas de. Livros e revistas para professores: configuração do material impresso e circulação internacional de modelos pedagógicos. In: Pintassilgo, Joaquim; Carvalho, Marta Maria Chagas de; Mogarro, Maria João; Freitas, Marcos Cezar de (Orgs.). História da escola em Portugal e no Brasil: circulação e apropriação de modelos culturais. Lisboa: Edições Colibri, 2006.

Caspard, Pierre. La presse d'éducation et d'enseignement XVIIIe siècle - 1940. Répertoire analytique. Paris: INRP, 1991.

Catani, Denice Bárbara. Educadores à meia luz: um estudo sobre a Revista de Ensino da Associação Beneficente do Professorado Público de São Paulo (1902-1918). Bragança Paulista: EDUSF, 2003.

Correia, Antonio Carlos da Luz; Silva, Vivian Batista da. Manuais pedagógicos Portugal/Brasil, 1930 a 1971 - produção e circulação internacional de conhecimentos pedagógicos. Lisboa: Educa, 2002.

Dal Rosso, Sady (Org.). Associativismo e sindicalismo em educação. Brasília: Paralelo 15, 2008.

Dalton, Mary. O currículo de Hollywood: quem é o "bom” professor, quem é a "boa" professora? Educação E̊ Realidade, Porto Alegre: UFRGS, v. 21, n. 1, p. 97-122, 1996.

Dubar, Claude. A socialização. Construção das identidades sociais e profissionais. Porto: Porto Editora, 1997. . A socialização: construção das identidades sociais e profissionais. São Paulo:

Martins Fontes, 2005.

Dubet, François. Le declin de l'institution. Paris: Éditions du Seuil, 2002. 
El declive de la institución: profesiones, sujetos e individuos ante la reforma del Estado. Tradução de Luciano Padilla. Barcelona: Gedisa, 2006.

Enguita, Mariano Fernandes. A ambiguidade da docência: entre o profissionalismo e a proletarização. Teoria e Educação, Porto Alegre: Pannonica, n. 4, p. 41-61, 1991.

Esteve, José Manoel. O mal-estar docente. Santa Catarina: EDUSC, 1999.

Fernandes, Ana Lúcia Cunha. O impresso e a circulação de saberes pedagógicos: apontamentos sobre a imprensa pedagógica na história da educação. In: MAGALdi, Ana Maria; Xavier, Libânia Nacif (Orgs.). Impressos e história da educação: usos e destinos. Rio de Janeiro: 7Letras, 2008. p. 15-29.

Goodson, Ivor F. A representação dos docentes: trazer de volta os professores. In:

Conhecimento e vida profissional: estudos sobre educação e mudança. Porto: Porto Editora, 2010. p. 63-78.

Hilsdorf, Maria Lúcia. Da circulação para a circularidade: propagação e recepção de ideias educacionais e pedagógicas no oitocentos brasileiro. In: Pintassilgo, Joaquim; Freitas, Marcos Cezar; Mogarro, Maria João; Carvalho, Marta Maria Chagas de. (Orgs.). História da escola em Portugal e no Brasil: circulação e apropriação de modelos culturais. Lisboa: Edições Colibri, 2006. p. 65-88.

Huberman, Michael. O ciclo de vida profissional dos professores. In: Nóvoa, Antônio (Org.). Vida de professores. 2. ed. Porto: Porto Editora, 2007. p. 31-61.

Hutmacher, Walo. A escola em todos os seus estados: das políticas de sistemas às estratégias de estabelecimento. In: NóvoA, Antônio (Coord.). As organizações escolares em análise. Lisboa: Dom Quixote, Instituto de Inovação Educacional, 1992. p. 47-74.

JAÉn, Marta Esther Jiménez. Os docentes e a racionalização do trabalho em educação: elementos para uma crítica da proletarização do trabalho docente. Teoria e Educação, Porto Alegre: Pannonica, n. 4, p. 74-89, 1991.

Lawn, Martin. Os professores e a fabricação de identidades. In: NóvoA, Antônio; Schriewer, Jürgen (Orgs.). A difusão mundial da escola. Lisboa: Educa, 2000. p. 69-84.

LÉLIs, Isabel; Xavier, Libânia Nacif. O ofício docente na voz de suas lideranças sindicais. Sísifo. Revista de Ciências da Educação, Lisboa: Universidade de Lisboa, p. 24-35, 2009. Disponível em: <http://sisifo.fpce.ul.pt>. Acesso em: 12 maio 2012.

Lima, Jorge Ávila de. Questões centrais no estudo das culturas profissionais dos professores: uma síntese crítica da bibliografia. Educação, Sociedade e Culturas, Porto, n. 13, p. 59-103, 2000.

Lopes, Sônia de Castro; Martinez, Sílvia. A emergência de escolas normais no Rio de Janeiro do século XIX: Escola Normal do Município da Corte e Escola Normal de Campos. Revista Brasileira de História da Educação, Maringá: SBHE, n. 15, p. 53-77, 2007. Disponível em: <http://www.rbhe.sbhe.org.br/index.php/rbhe/article/view/122>. Acesso em: 23 abr. 2012.

Magaldi, Ana Maria Bandeira de Mello; Neves, Carla Villanova. Valores católicos e profissão docente: um estudo sobre representações em torno do magistério e do "ser professora” (1930-1950). Revista Brasileira de História da Educação, Maringá: SBHE, n. 15, 2007, p. 100-115. Disponível em: < http://www.rbhe.sbhe.org.br/index.php/rbhe/article/ view/122>. Acesso em: 23 abr. 2012. 
Mendonça, Ana Waleska. A fragmentação dos estudos secundários e seus efeitos sobre o processo de profissionalização dos professores. Sísifo. Revista de Ciências da Educação, Lisboa, n. 11, p. 5-14,2010. Disponível em: $\langle$ http://sisifo.fpce.ul.pt/?r=27\&p=5>. Acesso em: 23 abr. 2012.

. Cardoso, Tereza Fachada. A gênese de uma profissão fragmentada. Revista Brasileira de História da Educação, Maringá: SBHE, n. 15, p. 31-52, 2007. Disponível em: $<$ http://www.rbhe.sbhe.org.br/index.php/rbhe/article/view/119>. Acesso em: 23 abr. 2012. Mogarro, Maria João. Bibliotecas particulares e saberes pedagógicos: circulação e apropriação de modelos culturais. In: Pintassilgo, Joaquim; Carvalho, Marta Maria Chagas de; Mogarro, Maria João; Freitas, Marcos Cezar (Orgs.). História da escola em Portugal e no Brasil: circulação e apropriação de modelos culturais. Lisboa: Edições Colibri, 2006.

. Martinez, Sílvia. Os primeiros estudantes do ensino normal: origens sociais e formação de professores na segunda metade do século XIX em Portugal. In: Pintassilgo, Joaquim; Serrazina, Lurdes (Orgs.). A escola normal de Lisboa e a formação de professores. Lisboa: Edições Colibri, 2009. p. 61-78.

ZAIA, Iomar Barbosa. Do Palácio ao Calvário: escolas de formação de professores em Portugal na segunda metade do século XIX. In: Pintassilgo, Joaquim; Serrazina, Lurdes (Orgs.). A Escola Normal de Lisboa e a formação de professores. Lisboa: Edições Colibri, 2009. p. 41-60.

NóvoA, António. Le temps des professeurs. Analyse socio-historique de la profession enseignante au Portugal (XVIII-XX siècle). Lisboa: Instituto Nacional de Investigação Científica, 1987. v. 2.

O espaço público da educação: imagens, narrativas e dilemas.In: Tempos de formação. Lisboa: Fundação Calouste Gulbenkian, 2002.p. 237-263.

. Evidentemente: histórias da educação. Lisboa: Editora ASA, 2005. Dicionário de Educadores Portugueses; Catálogo da Imprensa de Educação e Ensino e Bibliografia Portuguesa de Educação [CD-Rom].

. Catani, Denice. Estudos comparados sobre a escola no Brasil e em Portugal nos séculos XIX e XX. In: Congresso Brasileiro de História da Educação, 1., 2000, Rio de Janeiro. Anais... Rio de Janeiro: Sociedade Brasileira de História da Educação (SBHE), 2000, p.1-9.Disponível em: <http://www.sbhe.org.br/novo/congressos/cbhe1/ anais/028_antonio_denice.pdf $>$. Acesso em: 23 abr. 2012.

Oliveira, Dalila Andrade. A reestruturação do trabalho docente: flexibilização e precarização. Educação E̊ Sociedade, Campinas: CEDES, v.25, n. 89, p.1.127-1.144, set./dez. 2004. Disponível em: <http://www.scielo.br/scielo.php?script=sci_arttext\&pid=S010173302004000400003\&lng=en\&nrm=iso >. Acesso em: 23 abr. 2012.

. Duarte, Adriana Cancella; VIEIRA, Lívia Fraga (Coords.). Dicionário "trabalho, profissão e condição docente". Belo Horizonte: Grupo de Estudos sobre Política Educacional e Trabalho Docente (GESTRADO-UFMG), 2010. Disponível em: <http://www.gestrado. org/?pg=dicionario-apresentacao $>$. Acesso em: 24 fev. 2014. 
Perrenoud, Philippe. Práticas pedagógicas, profissão docente e formação: perspectivas sociológicas. Tradução de Helena Faria, Helena Tapada, Maria Carvalho, Maria Nóvoa. Lisboa: D. Quixote, 1993.

Pintassilgo, Joaquim; Alves, Alberto Luiz; Correia, Luiz Miguel; Felgueiras, Margarida (Orgs.). A história da educação em Portugal: balanço e perspectivas. Porto: Editora ASA, 2007. p. 35-72.

.Freitas, Marcos Cezar de; Mogarro, Maria João; Carvalho, Marta Maria Chagas de (Orgs.). História da escola em Portugal e no Brasil: circulação e apropriação de modelos culturais. Lisboa: Edições Colibri, 2006.

Serrazina, Lurdes. A escola normal de Lisboa e a formação de professores. Lisboa: Edições Colibri, 2009.

Souza, Donaldo Bello; Martinez, Silvia Alícia (Orgs.). Educação comparada, rotas de além-mar. São Paulo: Xamã, 2009.p. 167-220.

TARDIF, Maurice; Lessard, Claude; LahaYe, Louise. Os professores face ao saber: esboço de uma problemática do saber docente. Teoria e Educação, Porto Alegre: Pannonica, n. 4, p. 215-233, 1991.

Vicentini, Paula Perin; Lugli, Rosário Genta. História da profissão docente no Brasil: representações em disputa. São Paulo: Cortez, 2009.

. Rodrigues, Carla Marisa. Memórias de sala de aula: uma análise de autobiografias de professores. 1. ed. Lisboa: EDUCA, 2004.

Xavier, Libânia Nacif. Associativismo docente e construção democrática: Brasil-Portugal (1950-1980). Rio de Janeiro: FAPERJ; EDUERJ, 2013.

Xavier, Libânia Nacif; Mogarro, Maria João. Itinerários profissionais de professores no Brasil e em Portugal: redes de intercâmbio no contexto de expansão do movimento da Escola Nova. Revista História da Educação - ASPHE, Pelotas: ASPHE/FaE/UFPel, v. 15, n. 36, p. 117-136, 2011.

\section{SOBRE A AUTORA}

Libânia Nacif Xavier é doutora em educação pela Pontifícia Universidade Católica do Rio de Janeiro (PUC-Rio). Professora associada da Universidade Federal do Rio de Janeiro (UFRJ).

E-mail: libaniaxavier@hotmail.com 
